\title{
Relatos de gestores da Assistência Social, Educação e Segurança Pública sobre o enfrentamento da violência
}

\author{
Reports from Social Assistance, Education and Public \\ Security managers in coping violence
}

\author{
Luiza Jane Eyre de Souza Vieira', Antonia Karoline Araújo Oliveira², \\ Deborah Pedrosa Moreira ${ }^{3}$, Aline de Souza Pereira ${ }^{4}$, \\ Ana Maria Fontenelle Catrib ${ }^{5}$, Samira Valentim Gama Lira ${ }^{6}$
}

\begin{abstract}
Resumo
O estudo analisa a percepção dos gestores municipais no enfrentamento da violência contra crianças e adolescentes. Com abordagem qualitativa e indagações sobre políticas e ações concretizadas na prevenção e no enfrentamento do fenômeno, participaram 25 gestores da Educação, Assistência Social e Segurança Pública de 13 municípios da Região Metropolitana de Fortaleza, no Ceará, em 2010/2011. A análise de conteúdo na modalidade temática possibilitou a interpretação dos dados. O abuso sexual, a negligência e o trabalho infantil se destacaram, refletidos pela violência estrutural, desigualdade socioeconômica, vulnerabilidade familiar e drogadição. A escassez de recursos públicos, a desintegração setorial, a morosidade da justiça, a incipiência de políticas públicas e o despreparo dos gestores foram alguns percalços mencionados pelos participantes. O caráter plural do fenômeno demanda integração dos segmentos governamentais diante das iniquidades agregadas à gênese e à amplitude das violências.

Palavras-chave: criança; adolescente; gestão; políticas públicas; violência.
\end{abstract}

\section{Abstract}

The study examines the perception of municipal managers in fighting violence against children and adolescents. With qualitative approach and inquiries about policies and actions implemented to prevent and confront the phenomenon, 25 education, welfare and public safety managers from 13 municipalities in the metropolitan region of Fortaleza, in 2010 and 2011 participated. The content analysis in the thematic mode enabled the data interpretation. Sexual abuse, neglect and child labor stood subsumed by structural violence, socioeconomic inequality, family vulnerability and drug addiction. The lack of public resources, the sectoral breakdown, the slow pace of justice, the paucity of public policies and the managers' unpreparedness were some mishaps mentioned by participants. The phenomenon plural character demands government segments integration at the iniquities aggregated to the genesis and violence extent.

Keywords: children; adolescents; management; public policy; violence.

\footnotetext{
${ }^{1}$ Doutora em Enfermagem em Saúde Pública. Professora titular do Programa de Pós-Graduação em Saúde Coletiva da Universidade de Fortaleza (Unifor) Fortaleza (CE), Brasil.

${ }^{2}$ Mestre em Saúde Coletiva. Professora do Centro de Ciências da Saúde da Universidade de Fortaleza (Unifor) - Fortaleza (CE), Brasil.

${ }^{3}$ Mestre em Saúde Coletiva. Professora do Curso de Enfermagem do Centro Universitário Christus (Unichristus) - Fortaleza (CE), Brasil.

${ }^{4}$ Mestre em Saúde Coletiva. Professora do Curso de Enfermagem da Faculdades Nordeste (FANOR). Professora do Curso de Enfermagem da Estácio FIC Fortaleza (CE), Brasil.

${ }^{5}$ Doutora em Educação. Professora titular do Programa de Pós-Graduação em Saúde Coletiva da Universidade de Fortaleza (Unifor) - Fortaleza (CE), Brasil.

${ }^{6}$ Doutora em Saúde Coletiva. Professora do Centro de Ciências da Saúde da Universidade de Fortaleza (Unifor) - Fortaleza (CE), Brasil.

Trabalho realizado em 13 municípios da Região Metropolitana - Fortaleza (CE), Brasil.

Endereço para correspondência: Luiza Jane Eyre de Souza Vieira - Av. Washington Soares, 1321, Bloco S, Sala 1 - Edson Queiroz - CEP: 60811-905 - Fortaleza (CE), Brasil-Email: janeeyre@unifor.br

Fonte de financiamento: CNPQ (processo n ${ }^{0}$ 554397/2009-9); FUNCAP (processo n ${ }^{0}$ 9039/2008).

Conflito de interesses: nada a declarar
} 


\section{INTRODUÇÃO}

A despeito de a legislação assegurar direitos às crianças e aos adolescentes, as violências contra esse grupo desafiam os países ${ }^{1}$, desrespeitam os direitos humanos, perpetuam as desigualdades sociais e associam-se à ineficiente implementação das políticas públicas e assimetrias regionais ${ }^{2}$. É consenso na literatura que o enfrentamento a essas violências aponta a intersetorialidade como um dos eixos prioritários ${ }^{3}$.

Segundo essa lógica, apesar de a integralidade constituir a "tônica" dos planos de governos e da elaboração de programas, relatos de atores corresponsáveis por materializá-los mostram-se antagônicos, acríticos, reproduzem estigmas históricos e culturais, contrariam as diretrizes que sustentam os avanços e as conquistas de direitos assegurados na legislação a esse grupo em desenvolvimento ${ }^{4}$.

Tomando o enfrentamento às violências contra crianças e adolescentes, o estudo admite como violência todo ato/omissão cometido pelos pais, parentes, outras pessoas e instituições legitimadas capazes de causar danos físico, sexual e/ou psicológico à pessoa. Implica, de um lado, uma transgressão no poder/dever de proteção do adulto e da sociedade; de outra parte, uma negação do direito que esse grupo tem de ser tratado como sujeitos e pessoas em condições especiais de crescimento e de desenvolvimento 5 .

Nessa ótica, as violências contra esse grupo ampliam-se na medida em que os programas públicos de prevenção e de atendimento são insuficientes, faltam profissionais qualificados para a identificação e para o manejo, além de ocorrer omissão quanto ao cumprimento do arcabouço legal ${ }^{6}$.

Em busca desse enfrentamento, a literatura aponta o apoio social como um dos mais expressivos fatores de proteção ${ }^{7}$, ainda que apresente definições que dialogam com diversos construtos teóricos e práticas de cuidados ${ }^{8,9}$. Neste estudo, apreende-se como apoio social a tipologia das redes setoriais públicas, nomeadas como as que ofertam serviços específicos e especializados, resultantes das obrigações e dos deveres do Estado para com seus cidadãos ${ }^{4}$. Nesse entendimento, as exposições às violências ${ }^{10}$ aproximam-se das desigualdades sociais, do esvaziamento cultural e ético e das tênues relações interpessoais e sociais.

Apesar disso, as transformações sociais tendem a ser influenciadas pelas modalidades de gestão a que estão circunscritas. A diversidade de cultura e os hábitos nas regiões brasileiras, que reverberam na descentralização e nas pactuações políticas, justificam investigações regionalizadas, visto que a maioria das pesquisas restringe-se aos grandes centros ${ }^{11}$.

Diante do exposto e dos desafios colocados à gestão intersetorial, o estudo indaga como os gestores concebem as ações coordenadas em rede intersetorial, em seus municípios, para o enfrentamento das violências. Advoga-se que uma gestão centrada na resolubilidade de demandas sociais promove ações articuladas em prol de objetivos comuns.

Nessa lógica compreensiva, tem-se como objetivo analisar os relatos de gestores da Assistência Social, Educação e Segurança Pública no enfrentamento às violências contra crianças e adolescentes, em municípios da Região Metropolitana de Fortaleza (RMF), no Ceará.

\section{MATERIAIS E MÉTODOS}

Pesquisa qualitativa efetuada em 13 municípios da RMF: Aquiraz, Caucaia, Chorozinho, Eusébio, Guaiúba, Horizonte, Itaitinga, Maracanaú, Maranguape, Pacajus, Pacatuba, São Gonçalo do Amarante e Fortaleza. A interiorização e a disseminação da violência são visualizadas por meio do deslocamento dos polos dinâmicos e da nova geografia da violência homicida no país ${ }^{12}$.

A título de esclarecimento, essa região, atualmente, conglomera 15 municípios. Entretanto, a inserção de Cascavel e Pindoretama (LCE 78/09) ${ }^{13}$ deu-se em data posterior à aprovação do projeto no Comitê de Ética em Pesquisa da Universidade de Fortaleza (Parecer n. 351/2009).

Constaram como participantes representantes da gestão dos setores da Assistência Social, Educação e Segurança Pública, considerando-se como gestor o profissional e/ou representante da gestão com responsabilidade sanitária, que visam a novos valores e nova ética, pensada e praticada pela cogestão, no alcance dos objetivos organizacionais ${ }^{14}$. Atendendo a essa compreensão, participaram 25 sujeitos: Assistência Social (9), Educação (10) e Segurança Pública (6).

A particularidade do setor de Segurança Pública diz respeito à sua ínfima representação na contextura municipal, pois, em grande parte dos cenários, não havia órgão que representasse esse setor. Realizaram-se entrevistas com coordenadores da Guarda Municipal, Polícia Civil e/ou da Polícia Militar.

A abordagem aos participantes aconteceu em três fases: abordagem primária (contato telefônico), visita de apresentação (exposição da pesquisa no locus) e visita para a concretização das entrevistas. A coleta deu-se por meio de entrevistas semiestruturadas, realizadas em 2010 e 2011, incluindo-se a identificação do participante e as indagações sobre políticas e ações concretizadas pelos setores citados da gestão municipal quanto à prevenção e ao enfrentamento das violências contra crianças e adolescentes.

A codificação dos dados adveio do uso de duas variáveis: para qualificar o setor, deu-se pela ordem alfabética; para o município, alfanumérica. Dessa forma, a representação foi: Ação Social (A), Educação (E) e Segurança Pública (S); Aquiraz (1), Caucaia (2), Chorozinho (3), Eusébio (4), Fortaleza (5), Guaiúba (6), Horizonte (7), Itaitinga (8), Maranguape (9), Maracanaú (10), Pacajus (11), Pacatuba (12) e São Gonçalo do Amarante (13). 
A análise de conteúdo ${ }^{15}$, na modalidade temática ${ }^{16}$, fundamentou o plano analítico mediante leituras flutuantes e aprofundadas, agrupamentos de convergências e divergências, dos quais emergiram os temas: relatos dos gestores acerca das violências contra crianças e adolescentes; fatores determinantes da violência; enfrentamento intersetorial e dificuldades encontradas. A saturação teórica deu-se no momento da identificação de falas similares, redundantes, cujos conteúdos manifestos não agregaram elementos propulsores para novas inferências e interpretações ${ }^{16}$.

\section{RESULTADOS E DISCUSSÃO}

\section{Caracterização dos participantes}

Os participantes tinham em média 45 anos, maioria feminina (17), com graduações coerentes aos setores da gestão (Pedagogia e Serviço Social) - exceto cinco participantes da Segurança Pública, que não eram graduados -; detinham tempo médio de seis anos e meio na gestão, exercendo as funções de secretários municipais (7), coordenadores (6) e assessores técnicos (12).

\section{Relatos dos gestores acerca das violências contra crianças e adolescentes}

Nas falas dos participantes, as violências desafiam a intersetorialidade, crescem exponencialmente e suscitam incerteza quanto a seu enfretamento e soluções efetivas. Ressaltam como ponto positivo o envolvimento de lideranças comunitárias no "acompanhamento" dos casos e, ao mesmo tempo, reconhecem a vulnerabilidade desses líderes.

Aqui no município, temos grandes índices de violência, e o poder de resolução está longe de ser alcançado. (A6)

Os líderes comunitários acompanham de perto esse problema em sua localidade. (S2)

Representantes da Assistência Social e da Educação assumem a importância de desmistificar o uso da punição como disciplina, levando-se em consideração que é impossível se educar e transmitir valores por meio de atos violentos, como substitutivos de limites, diálogos e vínculos. Reiteram que o uso da violência contraria as concepções contemporâneas sobre a educação, nas quais se preconizam liderança e argumentação. Ressignificar histórias familiares constituídas na compreensão equivocada de violência e de disciplina, densamente enraizada na "transgeracionalidade", desafia a gestão pública.

Essa forma de educar por meio de palmadas não condiz com as novas concepções de educação. (E4)

$\mathrm{Na}$ cultura adultocêntrica, a agressividade e as rígidas normas são modos errôneos de educar, transmitidos por gerações como verdades inquestionáveis e mantendo-se à mercê das emoções do adulto ${ }^{17,18}$.

A compreensão dos gestores de que a violência também tem raízes na família foi apontada como dificuldade para romper o seu ciclo. Contudo, situações percebidas como negligência provavelmente refletem a violência estrutural a que esse grupo se encontra exposto ${ }^{19,20}$, assim como suas famílias e o entorno social.

Aqui no município, as crianças e os adolescentes são criados na rua, o relógio delas é o sol e a lua. Quando não estão nas escolas ou em algum projeto social, ficam expostas aos malefícios do mundo. (E4)

Muitas vezes, o ambiente domiciliar não é propício para o bem-estar da criança, fazendo com que as suas necessidades não sejam satisfeitas. (A2)

Apesar disso, o fato de os gestores atribuírem à gênese das múltiplas violências as estruturas familiares, a pobreza e, até mesmo, a política educacional não condiz com o papel a ser desempenhado por gestores. Esses "problemas e/ou desafios" não podem ser analisados como "forças externas" a sua ação profissional enquanto gestor de políticas, que se compromete com a construção e/ou resgate da cidadania.

Apesar de o caráter industrial dessa região contribuir para o crescimento socioeconômico, também favorece a exposição ao trabalho infantil. Essa compreensão confirma-se nas falas de gestores da Assistência Social e da Educação, ampliando a urgência do poder público em inserir esse grupo (crianças) em cenários participativos e produtivos de ações protagonistas e de desenvolvimento social.

Por ser município industrial, deparamo-nos com altos índices de trabalho infantil. As crianças acabam tendo que trabalhar para ajudar no sustento da casa. (A7)

O trabalho infantil interfere no aprendizado e traz consequências físicas e emocionais. (A10)

Embora municípios industriais ocupem destaque no Estado, surgem outros desafios: urbanização desorganizada; aumento da migração populacional na busca por emprego e por sustentabilidade; novas oportunidades que favorecem as exposições às violências sexuais, somando-se a outros contextos que acirram as desigualdades sociais, habitualmente associados à violência familiar ${ }^{21}$. Nesse sentido, as consequências do trabalho infantil são perversas para a saúde e cognição, com desdobramentos que balizarão a vida social e produtiva desse grupo $^{22}$.

Tornando o cenário mais complexo, as políticas públicas que objetivam minimizar as iniquidades sociais enfrentam embates há décadas para que sejam efetivadas. Nessa conjuntura, reafirma-se o compromisso das redes setoriais públicas integralizando a atenção aos problemas sociais ${ }^{23}$ e firmando-se como apoio político, cidadão e ético com os munícipes e sociedade. 


\section{Fatores determinantes da violência}

Nos relatos dos participantes, observou-se a pluralidade explicativa para as violências, reconhecidas pela complexidade em sua gênese, retratando histórias de vida individuais, familiares, assimetria na distribuição de renda e nas oportunidades de inclusão social ${ }^{5,18,24}$.

A miséria é tão grande que o serviço público não dá conta. As famílias são numerosas, as crianças chegam a passar necessidades. (E4)

Deslandes et al..$^{22}$ apontam para uma perspectiva dinâmica em que uma rede de fatores está interligada, inclusive os socioeconômicos. A miséria traz um elevado nível de pressões, estresses e frustrações.

Os participantes deste estudo mencionaram a drogadição como um grave problema que contribui para a expansão das violências que alcançam o grupo em estudo ${ }^{25,26}$. O homicídio, expressão fatal da violência, cresce nessa faixa e mostra uma relação complexa com as redes do narcotráfico ${ }^{27}$.

Droga é como folha seca no verão e o tráfico é meio de vida. Crianças são aviões, avós, traficantes, e pais, usuários. (E4)

O vício do crack está predominando em nossa região. (S2,8)

A associação do consumo abusivo de drogas lícitas e ilícitas à desagregação familiar está posta na literatura ${ }^{10,28}$. Sobre o narcotráfico, a sociedade convive com esse desafio $0^{29,30}$, anteriormente adstrito nas metrópoles e que, ultimamente, desafia o poder público quanto a acompanhar sua interiorização e conter seu alcance sobre crianças e adolescentes.

Está havendo a disseminação da droga para as localidades rurais. Os traficantes e usuários distanciam-se das áreas centrais do município, pois nesses locais o policiamento se faz mais presente. (S2,8)

A incapacidade de controlar o uso de drogas ilegais é hoje um dos principais problemas. $\mathrm{O}$ mundo criminal se desenvolveu para fazê-las circular com uma logística que impressiona por sua eficácia ${ }^{31}$.

No espaço microssocial, a ausência de vínculos afetivos na família foi mencionada pelos sujeitos como propulsor de violências entre esse segmento, considerando que os atuais arranjos familiares não constituem referência de valores e de responsabilidades.

As mulheres têm filhos de vários homens, são meros objetos sexuais. A criança não tem a família como referência. Observamos situações de filhos frutos de relacionamentos passageiros. Os lares são desestruturados, muitas crianças passam necessidades, sendo sustentadas com aposentadoria dos avós. (E4,6, 7; A2,7)

A necessidade de afeto, de estímulo e de atenção nas relações entre pais e filhos é importante para o desenvolvimento da criança, para a transmissão de valores, para os relacionamentos sólidos que fundamentam a formação da personalidade e visão de mundo da criança ${ }^{32}$.
Em contraponto, os gestores devem entender que as famílias têm estruturas próprias de organização e reorganização, conforme demonstra a literatura ${ }^{33}$. Avaliar os arranjos familiares a partir de um determinado modelo preconcebido possivelmente acarreta novos tensionamentos e conflitos na oferta de uma atenção integral e resolutiva diante dos problemas que demandam coeso apoio social.

Esforços não devem ser poupados com vistas a se perceber a família como principal foco de atenção e o primeiro sistema com o qual o ser humano em desenvolvimento interage ${ }^{18}$. É encargo da gestão se empenhar para reduzir o hiato que permeia as desigualdades sociais.

\section{Formas de enfrentamento e dificuldades que permeiam a gestão}

Tomando como paralelo as recomendações para a redução das iniquidades sociais ${ }^{34}$, os participantes mencionaram políticas e ações realizadas para o enfrentamento à violência. A intersetorialidade destaca-se entre os depoimentos dos representantes da Educação e Ação Social.

Aqui nós temos uma rede de proteção que envolve vários setores. Agimos embricadamente, Conselho Tutelar, Comdica, Secretaria da Assistência Social, Educação, Saúde e Segurança. A gestão funciona como um novelo. Trabalhamos de mãos dadas. (E4)

Essa afirmação evidencia a importância da intersetorialidade comprometida com a prevenção, o controle e o enfrentamento da violência. Ressalta-se que a atuação de uma equipe que conjugue a experiência de profissionais de distintas áreas favorece atenção diferenciada aos problemas e às necessidades abarcados pelas violências ${ }^{35}$.

Outra iniciativa abraçada pela gestão educacional consiste na adoção de tempo integral nas escolas de ensino fundamental.

As crianças passam 10 horas ininterruptas na escola. É mais um meio de educar e proteger. (E4)

O programa Segundo Tempo permite que os alunos permaneçam na escola no turno seguinte ao seu horário de aula. Como gestor e educador, aumentar o tempo deles na escola contribui para o aprendizado, sem falar que eles ficam menos tempo nas ruas. $(\mathrm{E} 4,7)$

A fala dos gestores remete a uma dualidade, pois, ao mesmo tempo em que se concebeu o turno integral como "medida protetora", em algumas instâncias, pode desencadear ou potencializar as violências nas escolas. Entende-se que instituir essa lógica requer, por parte da gestão, disponibilizar profissional qualificado para mediar conflitos, o que é cada vez mais comum nos espaços educacionais.

A violência no cenário escolar é mais antiga do que se pensa, porém, com o passar do tempo, ganhou traços mais graves e transformou-se em um problema social preocupante. A disseminação do uso de drogas, a formação de gangues e a 
facilidade de portar armas (inclusive as de fogo), potencializadas pela fragilidade dos vínculos comunitários e pela eclosão da violência urbana, incorporaram-se à escola, deixando-a de ser o porto seguro para a comunidade escolar ${ }^{36}$.

Representantes da Ação Social enfatizaram o trabalho com a família sobre a necessidade do afeto nas relações entre pais e filhos, salientando que o vínculo estabelecido entre a família e os profissionais (Saúde, Educação, Ação Social, Segurança, Conselho Tutelar) não pode ser desperdiçado.

O envolvimento da família nas ações preventivas e educativas é de fundamental importância. (E4,11; A2,6)

Nesse sentido, profissionais da rede intersetorial devem atender integralmente à família, envolvendo vítimas e abusadores, desmistificando o caráter punitivo e criminalizador que culturalmente prevalece ${ }^{18,37}$.

$\mathrm{Na}$ Assistência Social, existe um trabalho permanente de conscientização, educação e acompanhamento dos casos, por meio dos Centros de Referência de Assistência Social (CRAS), que abordam temas direcionados à família, desde modos afetuosos de educar os filhos até as possibilidades de acesso ao mercado de trabalho.

Os projetos sociais permitem que o CRAS desenvolva serviços para as famílias. Temos ações voltadas para as crianças, adolescentes, mulheres e idosos. Se tiver algum caso de violência, nós encaminhamos para o serviço especializado. (A1, 2, 4, 8)

Outras políticas e programas foram aludidos pelos gestores como forma de enfrentamento. Entre eles, destaca-se o fato de que esses municípios não detêm, em sua maioria, políticas municipais próprias para o enfrentamento do problema e tornam-se parceiros ou executores de programas estadual e/ou federal.

Aqui nós temos o PETI, Programa Peteca, Programas mais Educação e Segundo Tempo. Esses programas contribuem para erradicação do ciclo da violência, combatendo o trabalho infantil, incentivando crianças e adolescentes a permanecer na escola. (A1,2,4,8)

$\mathrm{Na}$ área social, o PROJOVEM, um programa federal, é frequentemente mencionado pelos participantes e tem o propósito de socializar e capacitar jovens para o ingresso no mercado de trabalho, incentivando o protagonismo juvenil. Importante ressaltar que o público-alvo não inclui crianças e adolescentes; no entanto, deve ser visto como estratégia de prevenção à violência, visto que promove a inclusão social e o exercício da cidadania ${ }^{38}$.

Os gestores da Segurança Pública salientaram o Programa Educacional de Resistência às Drogas e à Violência (PROERD) como o mais inclusivo no enfrentamento à violência no grupo em estudo. Agentes da Polícia Militar trabalham com crianças e adolescentes na prevenção contra as drogas. A iniciativa tem caráter social e preventivo; é desenvolvida nos Estados brasileiros por policiais militares selecionados/capacitados para o Programa.

Esse programa é desenvolvido pelos agentes de segurança. Essa parte da prevenção fica por conta do 'Ronda do Quarteirão'; eles são capacitados e depois vão às escolas falar de assuntos importantes como álcool e drogas. É um programa federal que desenvolvemos aqui no município. $(\mathrm{S} 2,5)$

É preciso esclarecer que o Ronda do Quarteirão é um programa de segurança pública do Ceará, iniciado em novembro de 2007 e definido como estratégia de policiamento próximo da sociedade, fazendo que os agentes de Segurança Pública sejam protagonistas da pacificação social ${ }^{39}$.

Algumas dessas experiências e inovações são geralmente reconhecidas como a base de uma polícia orientada para um acompanhamento e policiamento voltados à comunidade ${ }^{40}$. Além da iniciativa do PROERD, gestores da Segurança enfatizaram a importância do policiamento ostensivo no combate à criminalidade. Essa visão reporta-se à óptica repressora não suficiente e tampouco efetiva.

Variadas recorrências foram percebidas em discursos dos gestores da Educação e Ação Social sobre os percalços que permeiam a gestão e impedem uma ação efetiva e oportuna passível de prevenir ou, até mesmo, controlar o problema que se desdobra de modo elementar, sem esforços conjugados em prol da prevenção em face da inexistência da intersetorialidade.

O enfrentamento da violência ocorre ainda de forma muito primária, não existe o trabalho de prevenção e também não existe a intersetorialidade. (S8)

Existe um Plano Municipal de Enfrentamento à Violência, no entanto se planeja, elabora-se, cria-se o plano todo bonitinho no papel, mas na hora de fazer acontecer as pessoas fogem. (S8)

Essas declarações são corroboradas na literatura, pois existem lacunas na maneira de atuação dos órgãos responsáveis pelo enfrentamento do problema, na medida em que as ações são fragmentadas, contingenciais e restritas a subgrupos populacionais e de áreas geográficas ${ }^{41}$. A complexidade do fenômeno traz como consequência a necessidade de integrar vários profissionais e esforços para anular barreiras disciplinares, fazendo com que os conselhos e os órgãos responsáveis não sejam meros retalhos, integrados por profissionais primordialmente alocados nos seus tradicionais setores ${ }^{42}$.

Representante da Educação revela que as ações voltadas para as crianças e os adolescentes são momentâneas, acontecendo geralmente quando está se aproximando das visitas para aprovação municipal do selo do Fundo das Nações Unidas para a Infância (UNICEF).

Gestores do setor da Segurança Pública também se posicionaram sobre as limitações, afirmando ainda ser ínfimo o esforço para conter a violência. Reafirmam que vários setores, não somente 
a Polícia Militar, devem mudar o foco e o modo de agir para que possam alcançar resultados.

Os depoimentos apontam temas que fragilizam a gestão: escassez de recursos financeiros; desorganização na estrutura governamental; desafio de ter as famílias ou responsáveis como parceiros.

Enfrentamos problemas financeiros sim, porque a verba até existe, mas aqui não chega. O dinheiro repassado para a Secretaria é restrito. (E3)

Aqui no município, os órgãos são separados: secretaria $A, B, C . \hat{E}$ muito difícil reunir todo mundo. O trabalho em equipe se torna difícil, pois não somos habituados a unir forças com os outros setores. (S8)

A gente faz festa na escola todas comparecem; quando são palestras e orientações, só vai uma minoria. (E3)

A inexistência de sintonia entre gestão e família impossibilita elaborações sociais pertinentes e atuantes na prevenção da violência contra esse grupo. É importante discutir sobre os possíveis determinantes da violência no contexto coletivo e familiar que convidam à participação social dos cidadãos. Esquivar-se de coparticipar e de responsabilizar-se possivelmente amplie o distanciamento da gestão e de redes setoriais públicas com a comunidade.

O desinteresse dos jovens em participar de ações e de projetos desenvolvidos pela gestão municipal para a prevenção da violência foi expresso pela Segurança Pública, justificando que a desmotivação pode associar-se à circulação de drogas nas cidades.

Os adolescentes estão entregues ao mundo do consumo de drogas e ao tráfico. Observo alguns adolescentes desinteressados em participar de nossas ações educativas. Nós, da segurança, fazemos o possível para que eles possam participar e interagir, mas às vezes fica difícil mesmo. $(\mathrm{E} 3,11)$

O uso e o abuso de drogas pelos adolescentes são cada vez mais efetivos e acarretam desdobramentos no desenvolvimento e na dinâmica familiar ${ }^{43}$. Gestores atentam para a falta de projetos maiores voltados para esse público, principalmente no que se diz respeito ao enfrentamento da droga. A literatura assinala que são frágeis as políticas públicas para a educação sobre drogas no Brasil, com ausência de ações que tomem como objeto o consumo de drogas e a juventude ${ }^{44}$.

Os sujeitos admitem e reconhecem falhas na própria gestão, advindas de um processo político e administrativo complacente e incentivador da ocupação de cargos públicos por pessoas sem qualificação científica, técnica e ética, atributos que devem legitimar o cargo exercido.

O problema é que, no Brasil, as portas da gestão são abertas para qualquer pessoa assumir um cargo público, mesmo que não tenha conhecimento suficiente. (S9)

A gente nota uma atecnia. Isso gera problemas lá na ponta, para a comunidade. Precisamos que os gestores se capacitem. (E1)
Tais reivindicações vão ao encontro da literatura, que reitera a exigência de aptidões individuais dos gestores públicos diante da complexidade da administração pública brasileira, a exemplo de: conhecimento da máquina pública, saber jurídico, capacidade de promover o envolvimento da sociedade, habilidades para lidar com o público, objetividade, orientação para resultados, perspectiva global, relacionamento interpessoal e visão sistêmica ${ }^{45}$.

Por fim, os gestores da Ação Social e Educação retomam as iniquidades sociais como um dos maiores desafios para um efetivo enfrentamento da violência contra esse grupo.

Aqueles que vivem na miséria, em uma condição crítica, não têm capacidades de refletir a problemática em que se encontram. (A1)

Como abordado, a violência é também atribuída às condições precárias da população, inerentes ao processo de desfiliação social que predispõe à vulnerabilidade de crianças e adolescentes. A esse respeito, a violência estrutural se expressa por meio das desigualdades sociais, apropriações e expropriações das classes e dos grupos sociais ${ }^{45}$.

Depreende-se que, para garantir esses direitos, as responsabilidades são compartilhadas pela família, sociedade e Estado; a divisão de responsabilidades atrela-se a uma rede integrada, com atuação setorial e serviços da sociedade. Advinda essa compreensão, o trabalho oriundo da rede de proteção aprimora estratégias para materializar políticas públicas, por meio de compromisso e de encargos compartilhados para atender às distintas demandas que circunscrevem essas violências ${ }^{46}$.

\section{CONSIDERAÇÕES FINAIS}

Nos relatos dos gestores municipais, emergiram diversas ações para o enfrentamento das múltiplas violências contra crianças e adolescentes, divergindo quanto às formas adotadas e afirmando lacunas para a execução dessas ações e inexistência intersetorial. Os participantes propuseram mudanças na dinâmica setorial, no sentido de favorecer o trabalho integrado, a comunicação e a troca sistemática de informações.

Os percalços enfrentados pela gestão perpassam pelos eixos estruturantes que conclamam debates contínuos com as esferas do governo e da sociedade. O caráter multicausal do fenômeno, decorrente de um contexto exclusivo, do poder do narcotráfico e da criminalidade urbana, que se somam à ineficiente implementação de políticas públicas, exige posições firmes, responsáveis e integradas aos segmentos governamentais e sociais, os quais, por sua vez, devem priorizar a redução das iniquidades que se associam à amplitude do problema, considerando que o desejável enfrentamento às violências contra crianças e adolescentes, nos municípios analisados, encontra-se em elaboração e carece de amplos debates coletivos que assegurem esforços políticos. 


\section{REFERÊNCIAS}

1. United Nations Children's Fund. Hidden in plain sight: a statistical analysis of violence against children. New York; 2014

2. Brasil. Lei no 8.069 de 13 de julho de 1990. Dispõe sobre o Estatuto da Criança e do Adolescente e da outras providencias. Presidência da República Federativa do Brasil, Brasília, 13 de julho de 1990.

3. Brasil. Conselho Nacional dos Direitos da Criança e do Adolescente. Plano nacional de enfrentamento da violência sexual contra crianças e adolescentes. Brasília; 2013.

4. Comerlatto D, Matiello A, Colliselli L, Renk EC, Kleba ME. Gestão de políticas públicas e intersetorialidade: diálogo e construções essenciais para os conselhos municipais. Revista Katálysis. 2007;10(2):265-71. http:// dx.doi.org/10.1590/S1414-49802007000200015.

5. Ferreira AL, Moura ATMS, Morgado R, Gryner S, Branco VMC. Crianças e adolescentes em situação de violência. In: Njaine K, Assis SG, Constantino P, editors. Impactos da violência na saúde. Rio de Janeiro: Fiocruz; 2009. p. 127-48.

6. Algeri S, Souza LM. Violência contra crianças e adolescentes: um desafio no cotidiano da equipe de enfermagem. Rev Lat Am Enfermagem. 2006;14(4):625-31. http://dx.doi.org/10.1590/S0104-11692006000400023. PMid:16967172.

7. Habigzang LF, Azevedo GA, Koller SH, Machado PX. Fatores de risco e de proteção na rede de atendimento a crianças e adolescentes vítimas de violência sexual. Psicol Reflex Crit. 2006;19(3):379-86. http://dx.doi. org/10.1590/S0102-79722006000300006.

8. Carlos DM, Ferriani MGC, Esteves MR, Silva LMP, Scatena L. O apoio social sob a ótica de adolescentes vítimas de violência doméstica. Rev Esc Enferm USP. 2014;48(4):610-7. http://dx.doi.org/10.1590/S0080623420140000400006. PMid:25338240.

9. Squassoni CE, Matsukura TS, Panúncio-Pinto MP. Apoio social e desenvolvimento socioemocional infantojuvenil. Rev Ter Ocup. Univ. 2014;25(1):27-35.

10. Moreira DP, Vieira LJ, Pordeus AM, Lira SV, Luna GL, Guimarães e Silva J, et al. Exposição à violência entre adolescentes de uma comunidade de baixa renda no Nordeste do Brasil. Cien Saude Colet. 2013;18(5):1273-82. http://dx.doi.org/10.1590/S1413-81232013000500012. PMid:23670455.

11. Coutinho RX, Santos WM, Folmer V, Puntel RL. Prevalência de comportamentos de risco em adolescentes. Cad Saude Colet. 2013;21(4):441-9. http://dx.doi. org/10.1590/S1414-462X2013000400013.

12. Waiselfisz JJ. Mapa da violência no Brasil: os jovens do Brasil. Rio de Janeiro: Flacso; 2014.

13. Waiselfisz JJ. Mapa da violência 2012: os novos padrões da violência homicida no Brasil. São Paulo: Instituto Sangari; 2011

14. Bardin L. Análise de conteúdo. São Paulo: Edições 70; 2011.

15. Minayo MCS. O desafio do conhecimento: pesquisa qualitativa em saúde. São Paulo: Hucitec; 2010

16. Avanci J, Assis S, Oliveira R, Pires T. Quando a convivência com a violência aproxima a criança do comportamento agressivo. Cien Saude Colet. 2009;14(2):383-94. http://dx.doi.org/10.1590/S1413-81232009000200008. PMid:19197414.
17. Weber LND, Viezzer AP, Brandenburg OJ. O uso de palmadas e surras como prática educativa. Estud Psicol. 2004;9(2):227-37. http://dx.doi. org/10.1590/S1413-294X2004000200004.

18. Minayo MCS. Conceitos, teorias e tipologias de violência: a violência faz mal a saúde individual e coletiva. In: Njaine K, Assis SG, Constantino P, editors. Impactos da Violência na Saúde. Rio de Janeiro: Fiocruz; 2009. p. 21-42.

19. Aranha MLA. Temas de filosofia. São Paulo: Moderna; 2005.

20. Bazon MR. Violências contra crianças e adolescentes: análise de quatro anos de notificações feitas ao Conselho Tutelar na cidade de Ribeirão Preto, São Paulo, Brasil. Cad Saude Publica. 2008;24(2):323-32. http://dx.doi. org/10.1590/S0102-311X2008000200011. PMid:18278279.

21. Centro de Defesa da Criança e do Adolescente. Monitoramento da política de atendimento às vítimas de violência sexual. Ceará; 2014

22. Deslandes SF, Souza ER, Minayo MCS, Costa CRBSF, Krempel M, Cavalcanti $\mathrm{ML}$, et al. Caracterização diagnóstica dos serviços que atendem vítimas de acidentes e violências em cinco capitais brasileiras. Cien Saude Colet. 2006;11(2):385-96.

23. Wieviorka M. Violência hoje. Ciênc Saúde Coletiva. 2006;11(Supl):11471153.

24. Minayo MCS, Souza ER. É Possível prevenir a violência? Reflexões a partir do campo da saúde pública. Ciênc Saúde Coletiva. 1999;4(1):7-23. http:// dx.doi.org/10.1590/S1413-81231999000100002.

25. Rabello PM, Caldas Jr AF. Violência contra a mulher, coesão familiar e drogas. Rev Saude Publica. 2007;41(6):970-8. http://dx.doi.org/10.1590/ S0034-89102007000600012. PMid:18066467.

26. Bastos FI, Bertoni N, Hacker MA, Grupo de Estudos em População, Sexualidade e Aids. Consumo de álcool e drogas: principais achados de pesquisa de âmbito nacional, Brasil. Rev Saude Publica. 2008;42(Supl 1):10917. http://dx.doi.org/10.1590/S0034-89102008000800013. PMid:18660930.

27. Silva JG, Valadares FC, Souza ER. O desafio de compreender a consequência fatal da violência em dois municípios brasileiros. Interface (Botucatu) 2013;17(46):535-47. http://dx.doi.org/10.1590/S1414-32832013005000022.

28. Oliveira AL, Chamon EMOQ, Mauricio AGC. Representação social da violência: estudo exploratório com estudantes de uma universidade do interior do estado de São Paulo. Educ Rev. 2010;(36):261-274.

29. Galduróz JC, Noto AR, Nappo SA, Carlini EA. Household survey on drug abuse in Brazil: study involving the 107 major cities of the country - 2001. Addict Behav. 2005;30(3):545-56. http://dx.doi.org/10.1016/j. addbeh.2004.08.004. PMid:15718070.

30. Zaluar A. Democratização inacabada: fracasso da segurança pública. Estud Av. 2007;21(61):31-49

31. Minayo MCS. A difícil e lenta entrada da violência na agenda do setor saúde. Cad Saude Publica. 2004;20(3):646-7. http://dx.doi.org/10.1590/ S0102-311X2004000300001. PMid:15263975.

32. Organização Mundial da Saúde. Relatório Mundial da Saúde: o financiamento da cobertura universal. Genebra; 2010.

33. Maluf ACRFD. Novas modalidades de família na pós-modernidade [tese]. São Paulo (SP): Faculdade de Direito, Universidade de São Paulo; 2010 
34. Abramavoy M, Avancini A, Oliveira H. Violência nas escolas: o bê-á-bá da intolerância e da discriminação. Brasília: Unesco; 2001.

35. Assis SG, Avanci JQ, Pesce RP, Oliveira RVC, Furtado LX. A violência familiar produzindo reversos: problemas de comportamento em crianças escolares [relatório de pesquisa]. Rio de Janeiro: Claves; 2007.

36. Martins CBG, Jorge MHPM. Abuso sexual na infância e adolescência: perfil das vítimas e agressores em município do sul do Brasil. Texto Contexto Enferm. 2010;19(2):246-55.

37. Brasil. Ministério do Desenvolvimento Social. Programa de erradicação do trabalho infantil [Internet]. 2014 [citado em 2014 mar 20]. Disponível em: http://www.mds.gov.br/assistenciasocial/peti.

38. Ceará. Governo do Estado. Projetos estruturantes. Ronda do quarteirão [Internet]. 2014 [citado 2014 mar 10]. Disponível em: http://www.ceara. gov.br/governo-do-ceara/projetos-estruturantes/ronda-do-quarteirao.

39. Programa Educacional de Resistência às Drogas [Internet]. 2014 [citado 2014 mar 10]. Disponível em: https: http://www.proerdbrasil.com.br/ oproerd/oprograma.htm.

40. Paixão ACW, Deslandes SF. Análise das políticas públicas de enfrentamento da violência sexual infanto-juvenil. Saúde Soc. 2010;19(1):114-26.
41. Nunes CB, Sarti CA, Ohara CVS. Profissionais de saúde e violência intrafamiliar contra a criança e adolescente. Acta Paul Enferm. 2009;22 (N. esp.):903-8.

42. Lopes RE, Malfitano APS. Ação social e intersetorialidade: relato de uma experiência na interface entre saúde, educação e cultura. Interface (Botucatu). 2006;10(20):505-15. http://dx.doi.org/10.1590/S1414-32832006000200016.

43. Soares CB, Campos CMS, Berto JS, Pereira EG. Avaliação de ações educativas sobre consumo de drogas e juventude: a práxis no trabalho e na vida. Trab Educ Saúde. 2011;9(1):43-62.

44. Vendrúscolo TS, Ribeiro MA, Armond LC, Almeida ECS, Ferriani MGC. As políticas sociais e a violência: uma proposta de Ribeirão Preto. Rev Latino-Am Enfermagem. 2004;12(3):564-7. http://dx.doi.org/10.1590/ S0104-11692004000300016.

45. Camargo CL, Alves ES, Quirino MD. Violência contra crianças e adolescentes negros: uma abordagem histórica. Texto Contexto - Enferm. 2005;14(4):608. http://dx.doi.org/10.1590/S0104-07072005000400019.

46. Fernandes APP, Mazza VA. Identificando potencialidades e fragilidades do trabalho em rede de proteção contra a violência na infância. BIS, Bol Inst Saúde. 2013;14(3):280-88.

Recebido em: Jun. 10, 2015 Aprovado em: Set. 08, 2015 